\title{
Avaliação dos riscos psicossociais associados às atividades de catação e triagem de materiais recicláveis
}

\section{Evaluation of psychosocial risks associated with recyclable activities and trials of recyclable materials}

\author{
Andrea Cecília Lima Varicelli-Meireles ${ }^{1}$ \\ Mônica de Abreu Azevedo ${ }^{2}$ \\ Neuza Maria da Silva ${ }^{3}$
}

\section{Resumo}

Este estudo foi elaborado com o objetivo de descrever o perfil socioeconômico, verificar as condições de trabalho e os possíveis riscos psicossociais que os catadores de materiais recicláveis estão sujeitos em suas atividades diárias, bem como o grau de satisfação em relação ao trabalho e à convivência com os colegas e familiares. A pesquisa foi desenvolvida junto aos filiados de uma associação de reciclagem de resíduos sólidos urbanos, localizada no município de Ubá/MG. O estudo foi descritivo de corte transversal. O levantamento dos dados foi realizado por meio da aplicação de um questionário estruturado aos catadores de materiais recicláveis, com o qual foram coletados dados sobre o perfil socioeconômico do entrevistado, composição familiar, condições de trabalho, sendo avaliados os riscos psicossociais relacionados à atividade de catação de materiais recicláveis. Os resultados demonstraram que os catadores estão expostos a inúmeros riscos e vivem em condições insalubres de trabalho; as maiores reclamações foram provenientes dos riscos ergonômicos. O perfil dos entrevistados, as condições de trabalho, juntamente com a percepção destes, assinalam circunstâncias propícias para 0 desenvolvimento de riscos psicossociais.

Palavras-chave: Risco Ocupacional; Saúde Mental; Trabalho Informal.

\begin{abstract}
This study was designed with the purpose of describing the socioeconomic profile, verifying the working conditions and the possible psychosocial risks in which recyclable waste pickers are subject in their daily activities, as well as their degree of satisfaction with work and coexistence with colleagues and family. The research was developed with members of an association of solid urban waste recycling, located in the municipality of Ubá / MG. The study was crosssectional descriptive. Data were collected through the application of a structured questionnaire to collectors of recyclable materials, through which data were collected on the socioeconomic profile of the interviewee, family composition, working conditions, and the psychosocial risks related to the activity of the sampling of recyclable materials. The results have shown that scavengers are exposed to numerous hazards and live in unhealthy working conditions; the biggest complaints came from ergonomic risks. The profile of the interviewees, working conditions, together with the perception of these, indicate circumstances conducive to the development of psychosocial risks.
\end{abstract}

Keywords: Occupational Risk; Mental Health; Informal Work.

\footnotetext{
${ }^{1}$ Mestra em Economia Doméstica pela Universidade Federal de Viçosa. Bacharel em Design de Produto pela Universidade do Estado de Minas Gerais (UEMG). E-mail: andreavaricelli82@gmail.com

${ }^{2}$ Doutora em Engenharia Hidráulica e Saneamento pela Universidade de São Paulo. Professora do Departamento de Engenharia Civil da Universidade Federal de Viçosa. E-mail: monica.azevedo@ufv.br

${ }^{3}$ Doutora em Economia da Família e do Consumidor pela Purdue University. E-mail: neuzams@ufv.br
} 


\section{INTRODUÇÃO}

A geração de resíduos vem crescendo a cada ano, aumentando a demanda por serviços de logística, infraestrutura e, principalmente, recursos humanos e financeiros. Segundo a Associação Brasileira de Empresas de Limpeza Pública e Resíduos Especiais (ABRELPE, 2015), o Brasil produz anualmente 79,9 milhões de toneladas de resíduos sólidos urbanos. Enquanto a população brasileira cresceu $0,8 \%$ em comparação com o ano de 2014, a geração total dos resíduos sólidos urbanos apresentou um acréscimo de 1,7\% em 2015, refletindo, também, no setor de limpeza pública que movimentou cerca de $\mathrm{R} \$ 27,5$ bilhões registrando 353,4 mil postos de trabalho direto no mesmo ano.

Associado a esse crescimento, milhões de empregos informais são gerados a partir da reciclagem de resíduos. Um estudo realizado pelo Instituto de Pesquisa Econômica Aplicada (IPEA, 2013) que realizou um diagnóstico sobre os Catadores de Resíduos Sólidos, estimou entre 400 e 600 mil o número de catadores em atividade no país. Em comparação com os dados fornecidos pela ABRELPE, inúmeras pessoas vivem na informalidade e muitas sobrevivem de atividades relacionadas aos resíduos sólidos urbanos.

O perfil socioeconômico dos catadores brasileiros, traçado pelo IPEA (2013) com base nos dados do Censo Demográfico 2010 e da Pesquisa Nacional por Amostragem de Domicílios (PNAD) de 2012, evidencia que 66\% destes trabalhadores são negros, com idade média de 39 anos; 93,3\% residem em áreas urbanas; apenas 38,6\% possuem trabalho formal; a remuneração média recebida pelo trabalho é de $\mathrm{R} \$ 571,56$; para cada catador, estima-se que quatro pessoas da família dependam da renda gerada por sua atividade; 15,4\% contribuem para a previdência; e $20,5 \%$ é a taxa de analfabetismo entre os catadores. Segundo o IPEA (2013), a atividade do catador de materiais recicláveis não é recente, há registros desde o século XIX sobre a existência de catadores em atividade paralela durante todo o processo de urbanização do país. Eles "(...) realizam um serviço de utilidade pública muito importante no contexto atual das cidades, atuando na coleta de materiais para reciclagem que, caso fossem descartados, ocupariam maior espaço em aterros sanitários e lixões" (IPEA, 2013, p. 05). Estes trabalhadores vivem em ambientes de inúmeras precariedades, representando a parte mais vulnerável na cadeia de valor da reciclagem, sendo expostos diariamente a vários riscos provenientes dos resíduos.

Dentre os riscos que já foram convencionados, como os riscos químicos, biológicos, físicos, mecânicos e ergonômicos, há também os riscos psicossociais que, nos últimos anos, têm sido reconhecidos como um dos maiores desafios para a saúde e segurança dos trabalhadores (COSTA; SANTOS, 2013). De acordo com a Agência Europeia para a Segurança e a Saúde no 
Trabalho (2007, p. 01), os riscos psicossociais "estão relacionados com a forma como o trabalho é concebido, organizado e gerido, bem como com o seu contexto econômico e social, suscitam um maior nível de stress e podem originar uma grave deterioração da saúde mental e física". A perspectiva psicossocial dos trabalhadores e suas consequências é considerada como uma das áreas de pesquisa mais relevante para o futuro, "face às evidências da sua relação com o aumento de processos patológicos nos trabalhadores" (VILLALOBOS, 2004 apud COSTA; SANTOS, 2013, p. 40).

Dentre as patologias e transtornos de comportamento e da emoção que são desencadeados pelo trabalho, estudos evidenciaram a presença de depressão, de alterações de humor, distúrbios do sono, esgotamento físico e mental, tentativas de suicídio, uso de bebidas alcoólicas, tabagismo, fadiga, ansiedade, Síndrome de Burnout, hipertensão arterial, problemas cardiovasculares, cefaleia, gastrite e diabetes (CARAN, 2007; MELO; SILVANY NETO, 2012; OLIVIER; PEREZ; BEHR, 2011; PRIMO; PINHEIRO; SAKURAI, 2007 apud JACINTO; TOLFO, 2017). O desconforto emocional causado pelo nível de estresse, acompanhado pela vulnerabilidade, a insatisfação com o trabalho, a fadiga crônica, o neuroticismo e a extroversão, a ansiedade e o auto-conceito, são alguns dos fatores que aumentam a incidência de desenvolver distúrbios de comportamento (MARTINS, 2004). De acordo com a Secretaria de Previdência e o Ministério da Fazenda do Brasil (2017), os transtornos mentais e comportamentais classificaram-se, no período compreendido entre 2012 e 2016, como a terceira maior causa de afastamento por incapacidade no Brasil. O estresse, as condições precárias de trabalho, a ansiedade, a fadiga patológica e a insegurança estão entre alguns dos fatores que podem desencadear riscos psicossociais que, atualmente, são considerados um dos maiores desafios em termos de saúde pública para o século XXI.

A Organização Internacional do Trabalho (OIT, 2000 apud Secretaria de Segurança Pública de Santa Catarina, 2010),

\footnotetext{
“(...) reconhece que, para o século XXI, o trabalho estará se convertendo em um fator determinante e gerador de quadros neuróticos e desestabilizadores da saúde mental. Dentre os quadros mais comuns de adoecimento relacionados ao trabalho, e incapacitantes, destacam-se os transtornos de adaptação, associados a quadros de ansiedade, estresse crônico e fadiga patológica, além dos transtornos de angústia e depressivos" (OIT, 2000 apud SECRETARIA DE SEGURANÇA PÚBLICA DE SANTA CATARINA, 2010, p. 05).
}

Os distúrbios referentes à saúde mental do trabalhador repercutem seriamente nos indivíduos e na produtividade da empresa, ocasiona diminuição no desempenho dos funcionários, eleva o índice de doenças, de acidentes, absenteísmo e rotatividade de pessoal 
(OIT, 2000). Assim sendo, Leka; et al (2015) evidenciam a importância de considerarem a saúde mental do trabalhador em sua totalidade, priorizando o estado de bem-estar psicológico no trabalho e não somente a ausência de distúrbios. Os esforços para combater problemas de saúde mental não devem se concentrar em problemas específicos de forma isolada, mas intervenções apropriadas para coibir uma ampla gama de fatores de risco à saúde mental, priorizando a prevenção e ao mesmo tempo o desenvolvimento de sensibilização e facilitação do tratamento. O Conselho Regional de Medicina do Estado de São Paulo (CREMESP, 2016) enfatiza que, o desafio para as equipes de segurança e saúde é desenvolver a consciência nas empresas e empresários, sobre a necessidade de substituir a exigência por resultados financeiros por outro conjunto de valores. "A saúde mental é o pilar de sustentação para o capital humano ${ }^{4}$, sendo condição básica para a qualidade de vida e para a participação efetiva do indivíduo na sociedade e na geração de renda" (CREMESP, 2016, p. 314).

Martins (2004) esclarece que o indivíduo nutre expectativas compensatórias em relação ao trabalho, não somente expectativa financeira e material, mas também psicológicas e sociais. Segundo o CREMESP (2016, p. 96), "as pessoas que trabalham investem o melhor de si e esperam que sua contribuição seja reconhecida". Quando ocorre o reconhecimento, o trabalhador ressignifica os sofrimentos psicológicos que, por ventura, tenha sofrido; compreende que seus esforços colaboraram à organização do trabalho e se torna um individuo diferente após o reconhecimento. Contudo, "existem condições de trabalho que não proporcionam ao indivíduo oportunidades para desenvolver a sua autoestima. Outras, não garantem sequer a segurança ou não satisfazem, adequadamente, as necessidades sociais das pessoas" (MARTINS, 2004, p. 257). "[...] O trabalho desprovido de significação, sem suporte social, não reconhecido ou que se constitua em fonte de ameaça à integridade física e/ou psíquica, pode desencadear sofrimento psíquico", conforme salienta o Ministério da Saúde (BRASIL, 2001, p. 161).

O ambiente de trabalho saudável é indispensável para a saúde física e mental do trabalhador. Segundo a Organização Mundial da Saúde (OMS) o ambiente só é salutar quando "[...] os trabalhadores e os gestores colaboram para o uso de um processo de melhoria contínua da proteção e promoção da segurança, saúde e bem-estar de todos os trabalhadores e para a sustentabilidade do ambiente de trabalho" (OMS, 2010, p. 6). Neste sentido, a OMS aponta quatro áreas-chave que podem ser mobilizadas ou influenciadas visando alcançar um ambiente

\footnotetext{
4 "[...] O conceito de capital humano se refere ao conjunto de capacidades, conhecimentos, competências e atributos de personalidade que favorecem a realização de trabalho de modo a produzir valor econômico" (CREMESP, 2016, p. 64).
} 
de trabalho saudável: a) o ambiente físico de trabalho, b) o ambiente psicossocial, c) os recursos

para a saúde pessoal e d) o envolvimento da empresa na comunidade.

\begin{abstract}
"O ambiente físico de trabalho se refere à estrutura, ar, maquinário, móveis, produtos, substâncias químicas, materiais e processos de produção no local de trabalho. Estes fatores podem afetar a segurança e saúde física dos trabalhadores, bem como sua saúde mental e seu bem-estar. [...] O ambiente psicossocial do trabalho inclui a cultura organizacional, bem como atitudes, valores, crenças e práticas cotidianas da empresa que afetam o bem-estar mental e físico dos trabalhadores. Fatores que podem causar estresse emocional ou mental são muitas vezes chamados de "estressores" do local de trabalho. [...] Recursos para a saúde pessoal referem-se aos serviços de saúde, informação, recursos, oportunidades, flexibilidade, e outros ambientes de apoio que uma empresa proporciona aos trabalhadores para apoiar ou incentivar os seus esforços em melhorar ou manter estilo de vida saudável, bem como de acompanhar e apoiar sua saúde física e mental. [...] As empresas exercem impacto sobre as comunidades nas quais operam e são impactadas por estas. A saúde dos trabalhadores, por exemplo, é profundamente afetada pelo ambiente físico e social da comunidade em geral. A participação da empresa na comunidade se refere às atividades nas quais uma empresa pode participar, ou conhecimentos e recursos que pode prover para apoiar o bem-estar físico e social de uma comunidade em que atua. Isso inclui especialmente os fatores que afetam a saúde física e mental, a segurança e o bem-estar dos trabalhadores e suas famílias" (OMS, 2010, p. 7 $-11)$.
\end{abstract}

A prevenção dos riscos psicossociais provenientes da ocupação profissional encontra-se nas condições saudáveis de trabalho, mas em contrapartida, a situação de desemprego configura como o maior fator de agravamento da saúde mental (AMARO, 2013; LEKA, et al; 2015). Outro impasse seria o desenvolvimento de ambientes de trabalho saudáveis no setor econômico informal, pois segundo a OMS (2010, p.19), trata-se de um desafio mundial que ainda necessita ser enfrentado. Dentro dessa perspectiva e, na maioria das vezes, fora das estatísticas oficiais, estão os catadores de materiais recicláveis que por meio da prática de catação e triagem dos resíduos sólidos urbanos retiram seu sustento, vivem muitas vezes na informalidade, submetidos a condições precárias de trabalho, sendo diariamente expostos a inúmeros riscos advindos da atividade laboral. Diante da problemática envolvendo os riscos psicossociais e da situação socioeconômica dos catadores brasileiros apresentado pelo IPEA (2013), o presente artigo teve como objetivo básico descrever o perfil socioeconômico e verificar os possíveis riscos psicossociais em que estão expostos os catadores de materiais recicláveis.

\title{
METODOLOGIA
}

Neste estudo foi adotada uma abordagem descritiva, de corte transversal. Para o levantamento de dados utilizou-se de um questionário estruturado, os dados foram analisados utilizando o software livre: "GNU PSPP", versão 0.10.2 - GNU Operating System. 
A pesquisa foi realizada junto aos trabalhadores filiados da "Associação dos Catadores de Papel, Papelão e Material Reciclável de Ubá" (Reciclau), localizada no município de Ubá, em Minas Gerais.

\section{Área de Estudo}

A pesquisa foi realizada no município de Ubá/MG, localizado na Zona da Mata Mineira, com população estimada de 114.265 habitantes, área territorial de $407.452 \mathrm{~km}^{2}$, PIB de R\$ 21.359,99 per capita, conforme dados do Instituto Brasileiro de Geografia e Estatística (IBGE, 2018). Apontada como uma das principais cidades da Zona da Mata, Ubá se destaca pelo seu grande centro comercial e industrial, sendo núcleo de um dos principais polos moveleiros do Brasil.

O polo moveleiro de Ubá é composto pelas cidades de Guidoval, Piraúba, Rio Pomba, Rodeiro, São Geraldo, Tocantins e Visconde do Rio Branco. No ano de 2015, foi responsável por $45,2 \%$ do total de móveis produzido pelo estado de Minas Gerais, equivalendo a 28,2 milhões de peças, possibilitando 18.482 empregos formais (IEMI; ABIMÓVEL, 2016).

\section{Associação dos Catadores de Papel, Papelão e Materiais Recicláveis de Ubá (Reciclau)}

A Prefeitura Municipal de Ubá, em adequação à Política Nacional de Resíduos Sólidos (PNRS), que determinou a extinção dos lixões a céu aberto, transformou o lixão de Ubá em uma Estação de Transbordo de Resíduos Sólidos. Dessa forma, os resíduos domiciliares coletados no município são encaminhados para Estação de Transbordo e transferidos para o aterro sanitário localizado na cidade de Juiz de Fora/MG para disposição ambientalmente correta. Os resíduos inertes, oriundos da construção civil, são recolhidos por caçambas solicitadas previamente à Prefeitura e seguem para a Estação de Transbordo, onde são triturados e depositados no local, funcionando como aterro controlado para esses resíduos especificamente.

Desse modo, os catadores que utilizavam o lixão a céu aberto para coleta de materiais recicláveis foram encaminhados para o Galpão de Triagem, cedido pela Prefeitura Municipal de Ubá, onde funciona atualmente a Associação dos Catadores de Papel, Papelão e Materiais Recicláveis de Ubá (Reciclau), a qual possui oito trabalhadores associados.

Segundo a Reciclau, o compromisso da associação é "promover economia solidária através da geração de trabalho e renda e proteção ao meio ambiente através da coleta seletiva de materiais recicláveis" (RECICLAU, 2016). A associação recebe a colaboração da Agência de 
Desenvolvimento de Ubá e Região (ADUBAR), da Secretaria Municipal do Meio Ambiente, da Prefeitura Municipal de Ubá, da Secretária Municipal de Educação e da ECP Engenharia, empresa responsável pela limpeza urbana da cidade. Possui à sua disposição um caminhão para a coleta de material reciclável, o qual percorre alguns bairros específicos da cidade. Por meio de uma doação, efetuada pela Fundação Nacional de Saúde (FUNASA), foram instalados na cidade de Ubá mais de 240 containers para a coleta de materiais recicláveis. A Reciclau possui duas balanças e três prensas de materiais e, aguarda a doação de uma esteira de triagem.

Os materiais recolhidos pelos catadores da associação para a reciclagem são: plásticos em geral, sucatas de ferro, restos de peças automotivas, vergalhões de construção civil, geladeira, armários de aço, frízer, fogões, motores, resíduos eletroeletrônicos (computadores, telefones, pilhas, baterias, fax, impressoras, exceto televisores), papel misto e papelão, alumínio, metais, cobre, antimônio, inox, embalagens tetra pack, óleo de cozinha, vidros brancos para reutilização e garrafas de cerveja. Na Figura 1, são apresentadas fotografias da sede da Reciclau no momento da realização da pesquisa. Observa-se a disposição dos materiais ainda não triados, dos materiais já manipulados pelos trabalhadores, o ambiente de trabalho, a iluminação e as condições de realização do trabalho (postura dos trabalhadores).

Figura 1 - Fotografias retiradas na sede da Associação dos Catadores de Papel, Papelão e Materiais Recicláveis de Ubá (Reciclau) durante a execução do trabalho de catação e triagem dos materiais recicláveis (2016).

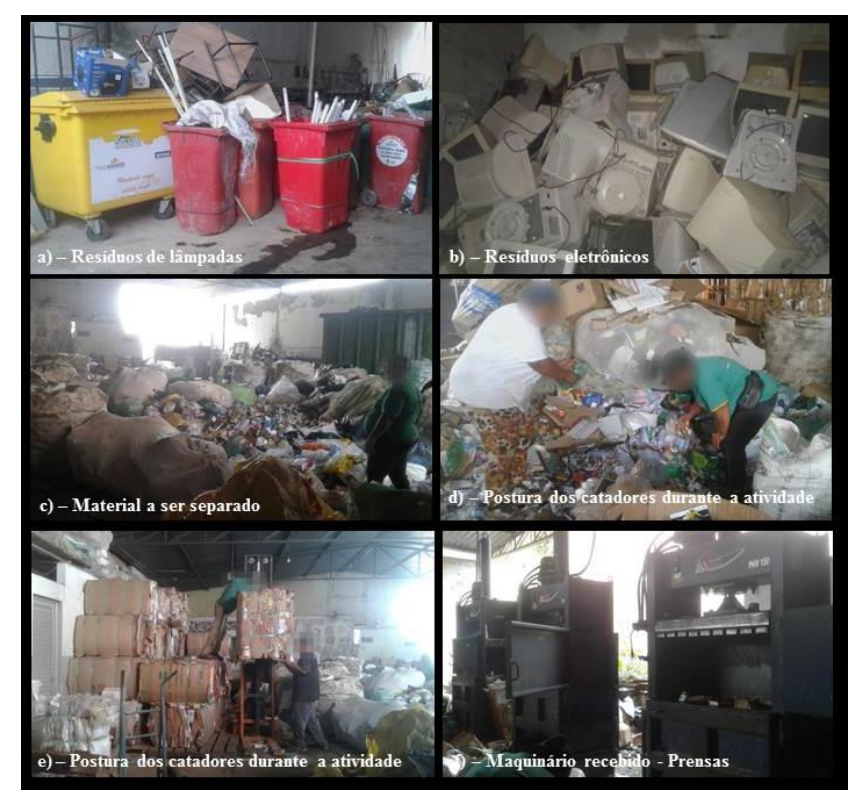

Fonte: A autora

A visita ao galpão da Reciclau oportunizou a observação de como o trabalho é realizado, da 'organização' e recepção dos materiais e da postura dos catadores de materiais recicláveis ao executar as tarefas diárias, ou seja, das condições de trabalho oferecidas aos catadores. 


\section{População e coleta de dados}

A população de estudo foi composta por oito catadores de matérias recicláveis que trabalham associados à Reciclau. Dois trabalhadores recusaram a participar da pesquisa, assim, o questionário foi aplicado a seis catadores vinculados à associação.

Para o levantamento dos dados foi realizado um Survey que, segundo Gil (1999, p. 70), é caracterizado pela "interrogação direta das pessoas cujo comportamento se deseja conhecer". Assim, os catadores foram diretamente interrogados por meio da aplicação de um questionário estruturado. O questionário foi dividido em quatro blocos: a) perfil do entrevistado; b) dados familiares e socioeconômicos; c) dados relativos à atividade de catação e d) avaliação dos riscos psicossociais.

As variáveis envolvidas no estudo para caracterizar o perfil socioeconômico dos entrevistados e de suas respectivas famílias foram: o sexo, idade, escolaridade, estado civil, composição familiar, a situação do imóvel de residência (próprio, alugado, cedido e outros), o local de residência, a renda familiar mensal e identificação do principal responsável pelo sustento familiar. Com o intuito de analisar a atividade de catação de materiais recicláveis, foram levantadas informações sobre: o tempo de exercício da atividade de catação de material reciclável, a renda mensal obtida, a carga horária de trabalho diária, a distância percorrida por dia para a coleta dos materiais recicláveis, as condições de transporte, a tipologia dos resíduos coletados e, por fim, foram levantados os problemas de saúde relacionados à atividade de catação, acometidos pelos entrevistados, no último ano. Também foi levantada a percepção do trabalhador em relação aos riscos de sua atividade e aos benefícios obtidos do trabalho associado.

Para analisar mais detalhadamente os possíveis riscos psicossociais, os entrevistados foram interrogados sobre o uso diário de algum medicamento e sua finalidade; a utilização de drogas ilícitas; o consumo de cigarros e de bebida alcoólica e a prática de atividade física ou esportiva. Com intuito de avaliar o grau de satisfação dos entrevistados em relação ao trabalho que exercem, bem como em relação a convivência com os colegas de trabalho e familiares, foi utilizada a Escala de Avaliação dos Danos Relacionados ao Trabalho (EADRT) validada por Mendes e Ferreira (2007 apud FACAS, 2013). Nessa escala foi solicitado aos entrevistados que ponderassem sobre os tipos de problemas físicos, psicológicos e sociais que consideravam causados, essencialmente, pelo seu trabalho como catador, marcando o número que melhor correspondesse à frequência com a qual tais "patologias" ocorreram nos últimos seis meses, sendo o número 1)- nunca, 2)- raramente, 3)- às vezes, 4)- frequentemente e 5)- sempre. $\mathrm{Na}$ 
EADRT constaram 23 variáveis, a saber: amargura, sensação de vazio, mau-humor, vontade de desistir de tudo, tristeza, perda da autoconfiança, solidão, insensibilidade em relação aos colegas, dificuldade nas relações fora do trabalho, vontade de ficar sozinho, conflitos nas relações familiares, agressividade com os outros, dificuldade com os amigos, impaciência com as pessoas em geral, dores no corpo, dores no braço, dor de cabeça, distúrbios digestivos, dores nas costas, alterações no sono, dores nas pernas, distúrbios circulatórios, e alterações no apetite. Os parâmetros de avaliação para a EADRT foram mensurados conforme orientação de Facas (2008), classificando-se em três níveis: a) acima de 3,7 - representa altos riscos psicossociais, demanda intervenções imediatas; b) entre 2,3 e 3,6 - representa risco médio, estado de alerta que demanda intervenções a curto e médio prazo; c) Abaixo de 2,2 - representa baixos riscos psicossociais.

\section{RESULTADOS E DISCUSSÃO}

Observou-se que a idade média da população estudada foi 49,6 anos; $66,6 \%$ eram do sexo feminino e $50 \%$ eram casados ou estavam em união estável. Quanto a escolaridade, 83,3\% possuíam apenas ensino fundamental incompleto. Cerca de $83 \%$ residiam em casa própria e $50 \%$ possuíam renda familiar mensal acima de dois salários mínimos. Entretanto, 33,3\% sobreviviam com menos de um salário mínimo, conforme dados da Tabela 1. A maioria dos entrevistados, $(66,67 \%)$, residia em áreas urbanas de Ubá/MG.

Tabela 1 - Perfil socioeconômico dos entrevistados - Ubá, MG, 2016

\begin{tabular}{|c|c|c|}
\hline Variável & Frequência & $\%$ \\
\hline \multicolumn{3}{|l|}{ Sexo } \\
\hline Feminino & 4 & 66,67 \\
\hline Masculino & 2 & 33,33 \\
\hline \multicolumn{3}{|l|}{ Estado Civil } \\
\hline Solteiro & 1 & 16,67 \\
\hline Casado ou em União Estável & 3 & 50,00 \\
\hline Separado & 1 & 16,67 \\
\hline Viúva & 1 & 16,67 \\
\hline \multicolumn{3}{|l|}{ Escolaridade } \\
\hline Ensino Fundamental Incompleto & 5 & 83,33 \\
\hline Ensino Fundamental Completo & 1 & 16,67 \\
\hline \multicolumn{3}{|l|}{ Renda Familiar Mensal } \\
\hline Menos de um salário mínimo* & 2 & 33,33 \\
\hline Até um salário mínimo e meio & 1 & 16,67 \\
\hline Mais de dois salários mínimos & 3 & 50,00 \\
\hline \multicolumn{3}{|l|}{ Tipo de Residência } \\
\hline Própria & 5 & 83,33 \\
\hline Cedida & 1 & 16,67 \\
\hline Idade & Anos & \\
\hline Idade média & 49,6 & \\
\hline Idade mínima & 41 & \\
\hline Idade máxima & 61 & \\
\hline
\end{tabular}

Fonte: Dados da pesquisa.

*Valor do salário mínimo vigor na época da pesquisa $=\mathrm{R} \$ 880,00$ 
Conforme pode se verificar na Tabela 2, a renda média mensal obtida da atividade de catação de materiais recicláveis era de $R \$ 530,00$. Este dado apresentou grande variação: o catador que recebia a maior quantia retirava $R \$ 880,00$ e o que menos recebia, ganhava $R \$$ 150,00 mensais. Cerca de 33\% dos entrevistados eram responsáveis pelo sustento familiar; $66,67 \%$ trabalhavam 8 horas por dia e exerciam a profissão de catador, em média, há mais de 13 anos. O que possuía maior tempo de profissão trabalhava há 35 anos como catador.

O perfil dos entrevistados é similar ao dos catadores brasileiros, descrito pelo IPEA (2013). A pesquisa do IPEA apontou que a maioria dos catadores residia em áreas urbanas, possuía baixa escolaridade e recebia uma renda média aproximada de $R \$ 500,00$. A metade deles era os únicos responsáveis pelo sustento familiar e nenhum contribuía para a previdência social.

Tabela 2 - Exercício da atividade de catação de materiais recicláveis - Ubá, MG, 2016

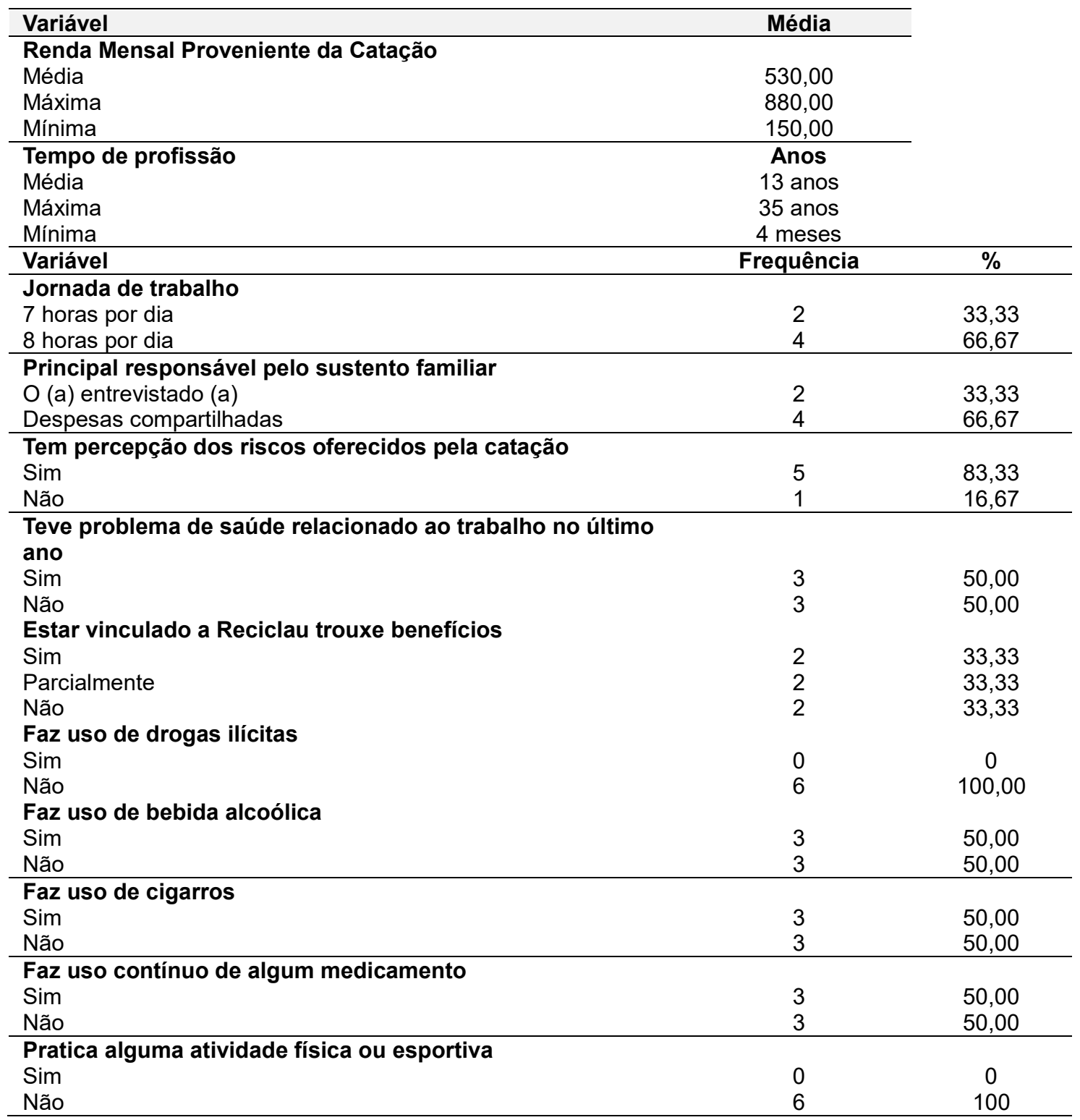

Fonte: Dados da pesquisa. 
Os resultados apontaram ainda que $83,3 \%$ dos participantes percebiam os riscos a que estavam submetidos devido à atividade de catação. Quanto ao uso de drogas lícitas e ilícitas, verificou-se que $50 \%$ faziam uso diário de medicamentos (depressão, pressão arterial e/ou artrose); $50 \%$ fumavam e consumiam bebidas alcoólicas com frequências diversas. Nenhum dos entrevistados fazia uso de drogas ilícitas, nem praticava esportes ou atividades físicas. Em relação ao nível de satisfação por ser associado da Reciclau, os resultados foram inconclusivos: $33,3 \%$ disseram não estar satisfeitos; 33,3\% responderam que estavam totalmente satisfeitos e $33,3 \%$ disseram estar parcialmente satisfeitos, pois apresentaram vantagens como melhoria nas condições de trabalho e desvantagens em relação à redução nos rendimentos e às relações conflituosas com colegas de trabalho.

Na Tabela 3 são apresentados os resultados obtidos da avaliação dos riscos psicossociais por meio da EADRT. As frequências das respostas foram agrupadas em dois grupos. O primeiro grupo refere-se aos participantes que marcaram as opções: 1 (nunca), 2 (raramente) ou 3 (as vezes) e, o segundo grupo, que assinalou 4 (frequentemente) ou 5 (sempre) como opção.

Tabela 3 - Escala de Avaliação dos Danos Relacionados ao Trabalho (EADRT), frequências relativas e médias dos itens - Ubá, MG, 2016.

\begin{tabular}{|c|c|c|c|}
\hline $\begin{array}{c}\text { Fator "Danos Psicologicos" } \\
\text { Itens }\end{array}$ & $\begin{array}{l}\text { Nunca, raramente } \\
\text { e às vezes }-F(\%)\end{array}$ & $\begin{array}{l}\text { Frequentemente e } \\
\text { Sempre } \\
\text { F (\%) }\end{array}$ & Média \\
\hline Vontade de desistir de tudo & 50,00 & 50,00 & 3,33 \\
\hline Mau humor & 66,67 & 33,33 & 2,83 \\
\hline Tristeza & 66,67 & 33,33 & 2,67 \\
\hline Amargura & 83,33 & 16,67 & 2,33 \\
\hline Sensação de vazio & 100,00 & ----- & 2,17 \\
\hline Solidão & 83,33 & 16,67 & 2,67 \\
\hline Perda da autoconfiança & 100,00 & --- & 1,83 \\
\hline \multicolumn{4}{|l|}{$\begin{array}{c}\text { Fator "Danos Sociais" } \\
\text { Itens }\end{array}$} \\
\hline Vontade de ficar sozinho & 66,67 & 33,33 & 2,83 \\
\hline $\begin{array}{l}\text { Insensibilidade em relação aos problemas de outras } \\
\text { pessoas }\end{array}$ & 66,67 & 33,33 & 2,50 \\
\hline Dificuldades nas relações fora do trabalho & 66,67 & 33,33 & 2,17 \\
\hline Impaciência com as pessoas em geral & 100,00 & ----- & 2,00 \\
\hline Conflitos nas relações familiares & 100,00 & ----- & 1,67 \\
\hline Agressividade com os outros & 100,00 & ----- & 1,33 \\
\hline Dificuldade com os amigos & 100,00 & ----- & 1,33 \\
\hline \multicolumn{4}{|l|}{$\begin{array}{c}\text { Fator "Danos Físicos" } \\
\text { Itens }\end{array}$} \\
\hline Dores no corpo & 33,33 & 66,67 & 4,00 \\
\hline Dores nos braços & 33,33 & 66,67 & 4,00 \\
\hline Dores nas pernas & 33,33 & 66,67 & 4,00 \\
\hline Dores nas costas & 50,00 & 50,00 & 3,33 \\
\hline Dor de cabeça & 50,00 & 50,00 & 3,17 \\
\hline Alterações no sono & 83,33 & 16,67 & 2,00 \\
\hline Distúrbios digestivos & 100,00 & ----- & 1,50 \\
\hline Distúrbios circulatórios & 100,00 & ----- & 1,50 \\
\hline Alterações no apetite & 100,00 & ----- & 1,33 \\
\hline
\end{tabular}

Fonte: Dados da pesquisa. 
Conforme demonstrado na Tabela 3, as queixas relatadas pelos entrevistados com maior frequência foram referentes aos danos físicos. Observou-se maior pontuação nas variáveis dores no corpo, nos braços e nas pernas como dores que frequentemente ou sempre persistem, indicando riscos altos (acima de 3,7) e demandando intervenção imediata. Os dados vão ao encontro com a elucidação da OMS (2010, p.19) de que, os "ambientes de trabalho saudáveis no setor econômico informal é um desafio mundial que necessita ser enfrentado".

Os resultados elevados destes itens, possivelmente, estão relacionados a postura e a condição de trabalho em que exercem as atividades diária. Conforme recomendado por Pinto e González (2008), observa-se na Figura 2, a melhor definição de layout para usinas de triagem. Com o intuito de minimizar os danos físicos e possibilitar maior eficiência no serviço de triagem, sugere-se a utilização de mesas de triagem para reduzir o esforço dos trabalhadores e proporcionar maior rendimento.

Figura 2 - Definição de layout eficiente com estabelecimento dos fluxos internos.

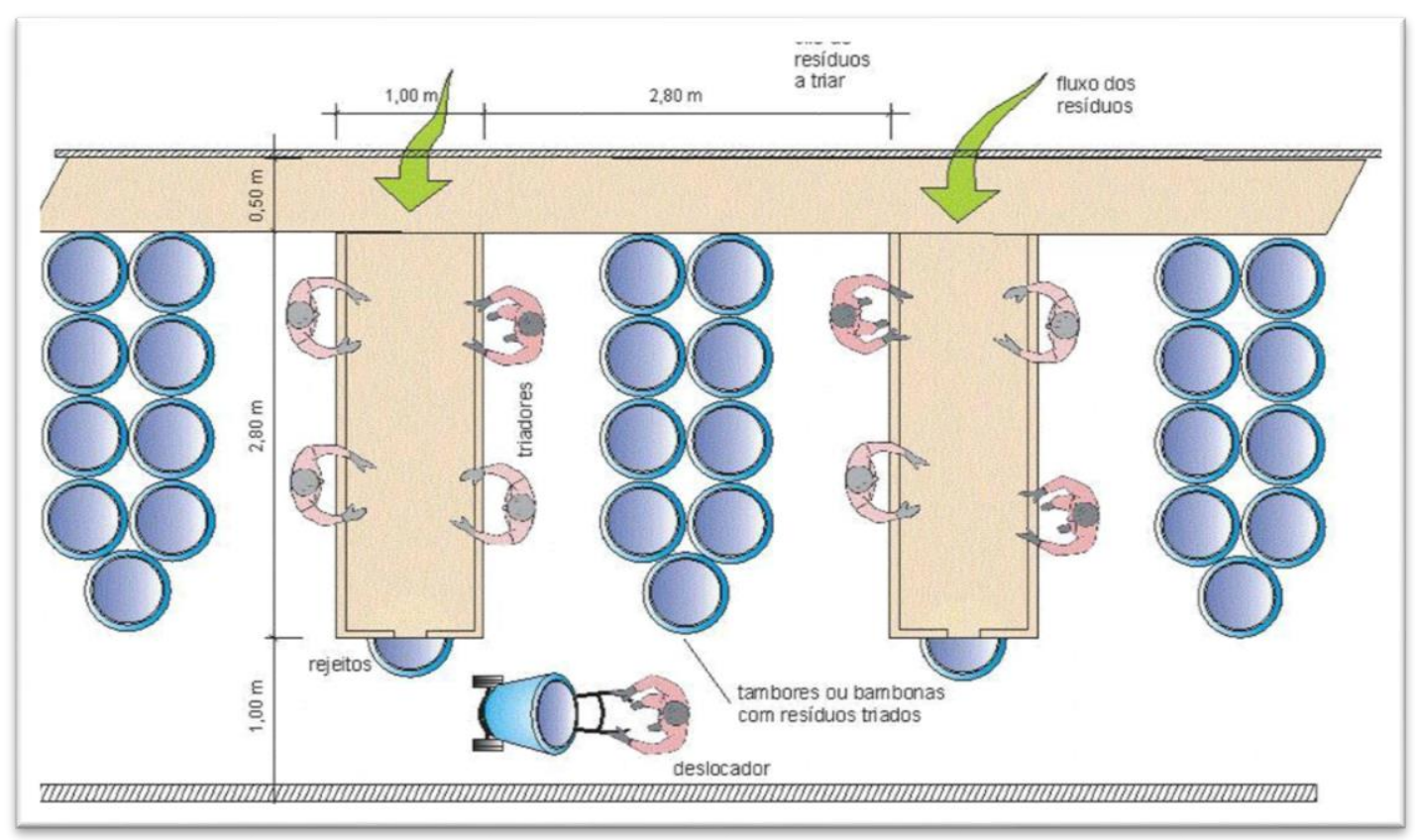

Fonte: Pinto e González, 2008, p. 28.

Nos danos psicológicos e sociais, os itens: vontade de desistir de tudo, mau humor, tristeza, vontade de ficar sozinho e insensibilidade em relação aos problemas de outras pessoas, apresentaram risco mediano. Representa um estado de alerta e demanda intervenções a curto e médio prazo.

Conforme recomendações da Fundação Estadual do Meio Ambiente (FEAM, 2006), para operação de uma usina de triagem algumas orientações básicas devem ser seguidas, dentre 
elas, destacam-se: (i) a obrigatoriedade do uso dos Equipamentos de Proteção Individual (máscaras, luvas, aventais, e botas), ao manusear os resíduos; (ii) a necessidade de trocar de uniformes no máximo a cada dois dias; (iii) a importância da varrição da área após o encerramento das atividades; (iv) a desinsetização semestral do local de trabalho; (v) a necessidade de vacinação contra tétano e difteria, febre amarela, hepatite A e hepatite B dos trabalhadores expostos a riscos de acidentes na coleta e manuseio dos resíduos. O documento enfatiza também os tipos de materiais que não devem ser recebidos para triagem: pilhas, baterias, pneus, embalagens vazias de agrotóxicos e lâmpadas fluorescentes. Apesar da maioria dos participantes $(83,3 \%)$ possuírem a percepção dos perigos que a profissão e o ambiente de trabalho oferecem, observa-se que os catadores não faziam uso de Equipamentos de Proteção Individual (EPI). Como forma de proteção, procuravam utilizar calçado fechado e cobrir a cabeça com boné ou lenço e utilizavam luvas esporadicamente. Verificou-se que não era realizada varrição do galpão da associação após o término das atividades, pois os materiais recolhidos se acumulavam pelo chão impossibilitando a limpeza. Além do mais, a associação recebia indevidamente, produtos eletroeletrônicos e seus componentes. De acordo com a Lei Federal 12305/2010 que instituiu a Política Nacional de Resíduos Sólidos (BRASIL, 2010), tais resíduos necessitam retornar aos fabricantes (comerciantes, importadores ou distribuidores) por meio da logística reversa ${ }^{5}$ para que os mesmos possam dar destinação correta a esses materiais.

Considerando as recomendações da FEAM, observou-se que os catadores não atentavam para nenhuma das exigências apresentadas ou não eram orientados para o exercício correto das atividades, apesar de terem a percepção dos perigos que a profissão oferece.

$\mathrm{Na}$ presente pesquisa constatou-se que, para os catadores, o fato de trabalharem envolvidos na Reciclau não apresentou significativas vantagens, apesar de ter proporcionado muitos benefícios. A associação possibilitou a padronização dos valores pelos quais os materiais eram vendidos e as doações recebidas de maquinário, facilitando e agilizando o serviço. $O$ fato de terem à sua disposição o caminhão para a realização da coleta minimizou o peso carregado e a quilometragem percorrida a pé, o que melhorou as condições de realização do trabalho. Apesar das vantagens, o serviço de triagem dos materiais ainda não foi sistematizado. Os catadores jogavam os resíduos a serem separados no chão e trabalhavam em cima da pilha de resíduos, como faziam no antigo lixão, há anos atrás, exercendo a mesma função. Repetiam

5 - "Logística reversa: instrumento de desenvolvimento econômico e social caracterizado por um conjunto de ações, procedimentos e meios destinados a viabilizar a coleta e a restituição dos resíduos sólidos ao setor empresarial, para reaproveitamento, em seu ciclo ou em outros ciclos produtivos, ou outra destinação final ambientalmente adequada" (LEI 12305/2010, Cap. II, art. $3^{\circ}$, inciso XII). 
inúmeras vezes a mesma postura, ficando muito mais vulneráveis aos riscos ergonômicos oferecidos pelo ambiente de trabalho.

Os resultados relacionados aos danos psicológicos e sociais foram medianos, porém são propícias as condições para que estes danos se estabeleçam e passem a representar altos riscos psicossociais. O ambiente insalubre, condições precárias de trabalho, baixo salário, o fato de não possuírem benefícios ou incentivos, falta perspectiva de crescimento profissional, conflitos entre os colegas de trabalho e a vontade de desistir de tudo, sentimento este descrito por $50 \%$ dos participantes como frequente ou sempre persistente. Além disso, há também os agravantes externos, como a visão distorcida que a sociedade possui desses trabalhadores, conforme relatado por Arantes e Borges (2013): "a atividade dos catadores é socialmente vinculada ao trato com o lixo, que está associado à ideia de miséria, doença e morte. É frequente que a população se refira a esses trabalhadores como catadores de lixo" (ARANTES; BORGES, 2013, p. 331).

Entretanto, apesar de todas as condições propícias para o desenvolvimento de certas doenças mentais, a ocorrência dependerá também de fatores subjetivos, como a capacidade de adaptação, nível de ansiedade, angústia e estresse que são individuais de cada trabalhador.

\section{CONCLUSÃO}

Objetivou-se, neste artigo, verificar os possíveis riscos psicossociais em que se encontravam os catadores de materiais recicláveis que trabalhavam associados à Reciclau, no município de Ubá/MG, bem como, buscou-se a mensuração destes riscos. Apesar dos riscos físicos terem sido identificados como os mais altos, pôde-se verificar pela realização deste estudo, o elevado risco psicológico e social que os catadores de materiais recicláveis estão sujeitos.

A pesquisa descritiva possibilitou a constatação de que o perfil socioeconômico dos participantes é similar ao perfil dos catadores brasileiros retratado pelo IPEA (2013), apresentando baixa escolaridade, renda média aproximada de $R \$ 550,00$ e sem trabalho formalizado. As condições econômicas e sociais apresentadas, aliadas a precariedade do ambiente de trabalho, conflitos entre os colegas de serviço, falta de perspectiva profissional, possível insatisfação com a associação e o estado emocional dos entrevistados, evidenciam que os trabalhadores estão vulneráveis aos riscos psicossociais.

Contudo, esses riscos, bem como os demais, podem ser amenizados oferecendo a esses profissionais melhores condições de trabalho, benefícios, seguridade e instrução para 
adequação às normas, cabendo ao poder público uma maior intervenção, propiciando a esses profissionais uma melhor qualidade de vida.

A atividade de catação de materiais recicláveis além de ser reconhecida como uma profissão deve ser reconhecida pelo poder público e pela sociedade civil como uma atividade de relevância social e ambiental, sendo os trabalhadores devidamente remunerados e reconhecidos com tal.

\section{REFERÊNCIAS}

AGÊNCIA EUROPEIA PARA A SEGURANÇA E A SAÚDE NO TRABALHO. Previsão dos peritos sobre os riscos psicossociais emergentes relacionados com a segurança e saúde no trabalho (SST). Facts, n. 74, ISSN 1681-2166. Bélgica, 2007. Google

ASSOCIAÇÃO BRASILEIRA DE EMPRESAS DE LIMPEZA PÚBLICA E RESÍDUOS ESPECIAIS. Panorama dos Resíduos Sólidos no Brasil. São Paulo, 2015. 04 jul. 2017. [Visualizar]

AMARO, António Duarte. A crise e os riscos psicossociais no âmbito de segurança e saúde no trabalho. D. d. Coimbra, Riscos Naturais, Antrópicos e Mistos. Homenagem ao Professor Doutor Fernando Rebelo, p. 569-584, 2013. Google

ARANTES, Bruno Otávio; BORGES, Livia de Oliveira. Catadores de materiais recicláveis: cadeia produtiva e precariedade. Arquivos Brasileiros de Psicologia; Rio de Janeiro, 2013. Google

BRASIL. Lei no 12.305/2010, de 2 de agosto de 2010. Institui a Política Nacional de Resíduos Sólidos; altera a Lei no 9.605, de 12 de fevereiro de 1998; e dá outras providências. Diário Oficial [da] República Federativa do Brasil. Brasília, DF, 2010. Google

BRASIL. Ministério da Saúde e Organização Pan-Americana da Saúde. Doenças relacionadas ao trabalho: manual de procedimentos para os serviços de saúde. Brasília, DF, 2001. Google

BRASIL. Secretaria de Previdência e Ministério da Fazenda. 1 Boletim quadrimestral sobre benefícios por incapacidade. Brasília, DF, 2017.

CONSELHO REGIONAL DE MEDICINA DO ESTADO DE SÃO PAULO. Saúde Mental e Trabalho. São Paulo, SP, 2016.

COSTA, Lúcia Simões; SANTOS, Marta. Fatores Psicossociais de Risco no Trabalho: Lições Aprendidas e Novos Caminhos. International Journal on Working Conditions, N. 5, jun. 2013. Google

FACAS, Emilio Peres. Protocolo de Avaliação dos Riscos Psicossociais no Trabalho Contribuições da Psicodinâmica do Trabalho. 2013. 191 f. Tese (Doutorado em Psicologia Social, do Trabalho e das Organizações) - Universidade de Brasília, Brasília, DF, 2013. Google

FUNDAÇÃO ESTADUAL DO MEIO AMBIENTE. Orientações Básicas para operação de usina de triagem e compostagem de lixo. Belo Horizonte, 2006. 
GIL, Antônio Carlos. Métodos e Técnicas de Pesquisa Social. 5. Ed. São Paulo: Atlas, 1999.

INSTITUTO BRASILEIRO DE GEOGRAFIA E ESTATÍSTICA. Estimativas da população residente com data de referência 1 de julho de 2018. Rio de Janeiro, 201829 ago. 2018 [Visualizar]

. PIB per capita. [Visualizar]

Área territorial brasileira. Rio de Janeiro, 2018. 29 ago. 2018. [Visualizar]

INTELIGÊNCIA DE MERCADO; ASSOCIAÇÃO BRASILEIRA DAS INDÚSTRIAS DO MOBILIÁRIO. Relatório Setorial da Indústria de Móveis no Brasil. São Paulo, SP, 2016.

INSTITUTO DE PESQUISA ECONÔMICA APLICADA. Situação Social das Catadoras e dos Catadores de Material Reciclável e Reutilizável. Brasília, DF, 2013.

JACINTO, Aline; TOLFO, Suzana da Rosa. Fatores psicossociais de risco no trabalho e Transtorno Mental Comum: uma revisão sistemática de estudos que utilizaram os instrumentos JCQ, JSS e SRQ-20. Revista de Psicologia da IMED, v. 9, n. 2, p. 107-124, 2017. Google Ecrossret

LEKA, Stavroula; JAIN, Aditya; IAVICOLI, Sergio; DI TECCO, Cristina. An Evaluation of the Policy Context on Psychosocial Risks and Mental Health in the Workplace in the European Union: Achievements, Challenges, and the Future. BioMed Research International, ID 213089, 2015. Google

MARTINS, Maria da Conceição de Almeida. Factores de Risco Psicossociais para a Saúde Mental. Revista Millenium - Repositório do Instituto Politécnico de Viseu, p. 255-268, 2004. Google

ORGANIZAÇÃO INTERNACIONAL DO TRABALHO. Mental Health in the Workplace: Situation Analyses, United Kingdom. Genebra, 2000. 29 ago. 2018. [Visualizar]

ORGANIZAÇÃO MUNDIAL DE SAÚDE. Ambientes de trabalho saudáveis: um modelo para ação: para empregadores, trabalhadores, formuladores de política e profissionais. Tradução do Serviço Social da Indústria. Brasília: SESI/DN, 2010. Google

PINTO, Tarcísio de Paula; GONZÁLEZ, Juan Luis Rodrigo. Elementos para a organização da coleta seletiva e projeto dos galpões de triagem. Ministério das Cidades e Ministério do Meio Ambiente, Brasília, DF, 2008. Google

RECICLAU - ASSOCIAÇÃO DOS CATADORES DE PAPEL, PAPELÃO E MATERIAL RECICLÁVEL DE UBÁ. Informações: Página do Facebook. 05 jul. 2017. [Visualizar]

SANTA CATARINA (Estado). Secretaria de Segurança Pública. Mapeamento das Fontes de Estresse em Profissionais da Segurança Pública do Estado de Santa Catarina. Florianópolis: DIFC/SSP - SENASP/MJ, 2010. 